\title{
Processing time as influenced by the number of elements in a visual display'
}

\author{
R. C. ATKINSON, ${ }^{2}$ J. E. HOLMGREN, AND J. F. JUOLA \\ STANFORD UNIVERSITY
}

In a visual-detection experiment, a display of several letters was presented, and $S$ was to report the presence or absence of a given target letter. Results clearly are incompatible with a selfterminating visual-scanning process as hypothesized by Sternberg (1967). Two models are considered, a serial exhaustive scanning process and a parallel exhaustive process, but findings from the present study do not provide a basis for differentiating between them.

In several experiments, Estes and Taylor $(1964,1966)$ have studied the visual-detection process for the case in which $S$ searches for one of a predesignated pair of letters (signal or critical elements) imbedded within a tachistoscopically presented display of noise letters. A forced-choice design was used with $S$ responding that he saw one or the other of the critical elements on every trial, even if the detection was uncertain. The models proposed to account for the results assume $S$ samples a proportion of the letters present on each trial, and then serially scans through them to determine which target letter was included in the display. If the target letter is among the letters sampled, $S$ makes the appropriate response after processing the critical element. If, however, the target letter is not included among the elements sampled on that trial, $S$ guesses one of the two alternatives. These models accurately predict an increase in error rate with an increase in the number of noise elements in the display, but a deeper analysis of the scanning process is difficult to achieve using their data primarily because of the somewhat random placement of letters within the display and the lack of latency measures.

By measuring response latencies in a similar experiment, Estes and Wessel (1966) were able to demonstrate that error latencies remain essentially constant across display sizes, indicating that $S$ continues processing elements in searching for a match with one of the target letters until some temporal criterion is reached (perhaps the point at which the registered image of the display has decayed beyond usefulness in extracting information), at which point $S$ guesses. The data also indicated that the search process might terminate with a correct response as soon as the target letter is processed. Estes and Wessel based both of these latter inferences upon latency data that had been corrected for guessing, admittedly leaving definite conclusions about the nature of the scanning process for further research.

Using a different paradigm, Sternberg (1966) has presented evidence for serial and exhaustive scanning of elements stored in memory. On each trial $\mathrm{S}$ was given a list of one to six digits to remember. A single test digit was then presented, and $S$ responded by pulling an appropriate lever to indicate whether or not the test digit matched any of those in memory. In this experiment there were virtually no errors, allowing latency scores to be used without correction. Potting latency against memory set size, Stemberg was able to draw two important conclusions: (a) The data could be fit by a straight line indicating a constant increase in latency for each additional item in the memorized list. (b) Independent of the size of the memory set, positive and negative responses take essentially the same amount of time. These results suggest that comparisons are made exhaustively between the test element and memory elements, i.e., even when a match is obtained the scan continues to the end of the list before a response is made.

Sternberg (1967) has expanded the initial experiment to include variations in the number of display elements as well as the number of elements in memory. On each trial $S$ was presented with anywhere from one to four digits to remember, and then was shown a tachistoscopic display containing one, two, or three digits in a linear array. The $S$ was instructed to make a positive response if the two sets had any elements in common, and a negative response if no elements in the two lists matched. From the response latency data $S$ ternberg concluded that $S$ begins the scan by comparing one item in the display with all memory items. After this comparison has been completed, a positive response is made if a match was detected; otherwise, another display item is selected and the comparison process is repeated. Thus, each scan of the memory list is exhaustive, while the scan of the display items is self-terminating. These conclusions were based on the observation that as the length of the memorized list increased, latencies for negative responses increased at a faster rate than those of positive responses for all display sizes greater than one item.

Support for Sternberg's (1967) representation of the scanning process has been offered by Nickerson (1966). In a task similar to Sternberg's paradigm, Nickerson found evidence for a selfterminating search for a target letter in a visually presented display. His data showed latencies to be inversely related to the number of elements that the memory and display lists had in common. Assuming a strictly serial comparison process, these results are incompatible with those predicted by an exhaustive scanning model. Nickerson points out that the high percentage of false negative responses in his study suggests that the search may terminate with a negative response after a certain amount of time has elapsed rather than terminating with the processing of a critical element in all cases. Although Sternberg does not report the percentage of false positive responses in his study, the same consideration may apply to that data.

Nickerson (1966) also tested for the effects of extended training on performance in the detection task. The results showed that both overall latency as well as the relative increase in latency with increasing display size tended to decrease with practice and continued to decrease through 22 consecutive daily sessions.

For the present study it was decided to apply the Sternberg (1966) paradigm to a visual-detection task like that of Estes and Taylor $(1964,1966)$ with the following modifications incorporated from both types of experiments: (a) A yes-no detection task was used, rather than a forced-choice design, to allow comparison of positive and negative responses. (b) The display letters were presented in a linear array with a relatively long exposure time to insure correct responding. This made it possible to use response latencies as the dependent variable, while eliminating the need to correct for guessing. (c) The Ss were run for several sessions to obtain sufficient data to examine individual performance and to determine the extent of practice effects. With these modifications it was hoped that the present study would lead to a more direct analysis of the scanning process. 


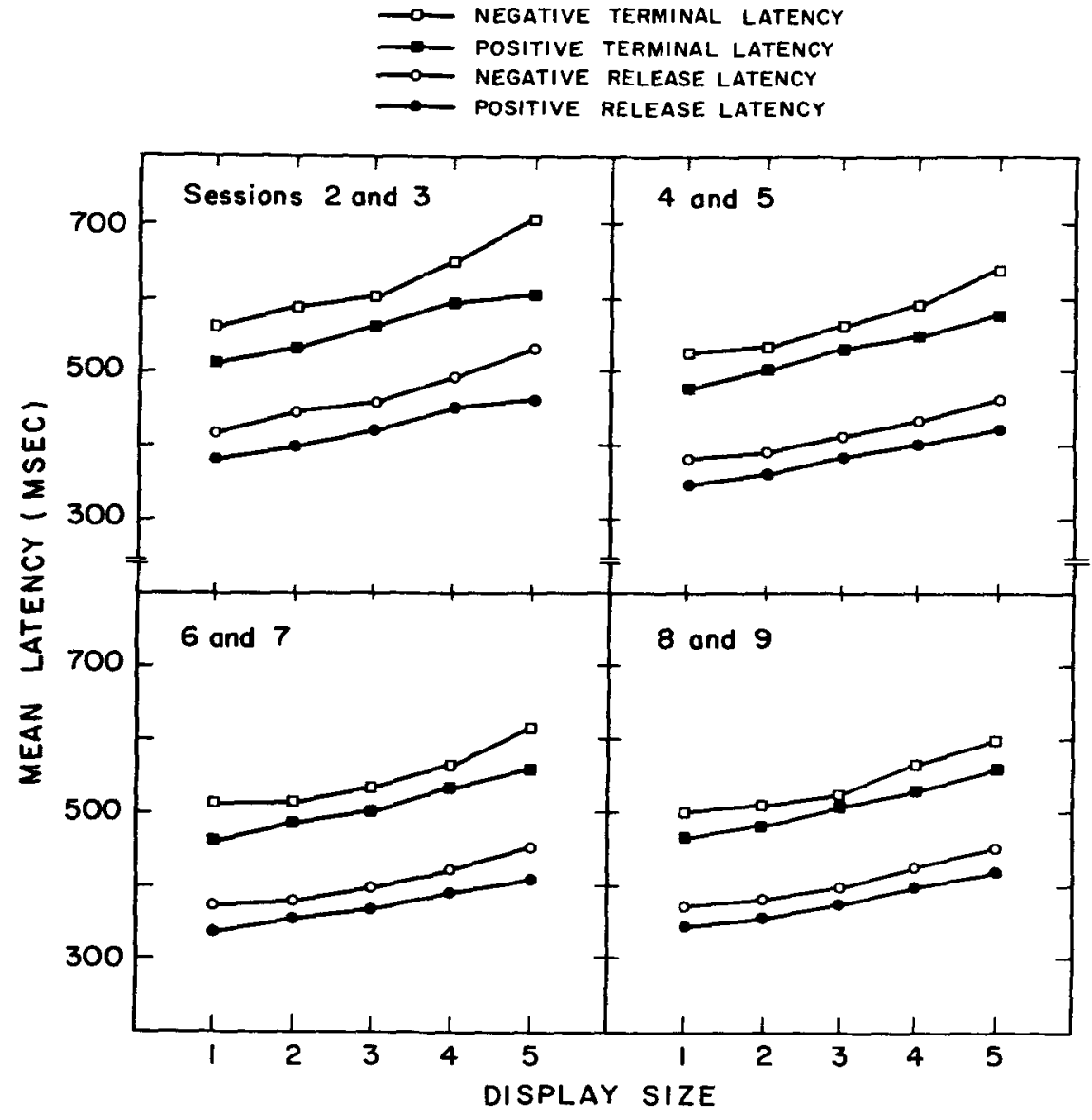

Fig. 1. Latency of positive and negative responses as a function of display size and session number for all $S s$ combined.

\section{METHOD}

The Ss were eight female Stanford University undergraduates with normal vision. Each was paid a total of $\$ 15.75$ for the nine sessions of the experiment. In all sessions the task was to scan a visually presented array of letters to determine the presence or absence of a specific letter. The 20 consonants were used for both the target letters (critical elements) and the nontarget letters (noise elements). The critical element was included in the display on half the trials.

The display slides were prepared from photographs of capital letters typed with an IBM Executive "Registry" electric typewriter. A dollar sign was used as a delimeter on each side of the display, with no additional spaces between the signs and the display letters. The array of letters varied from one to five elements in length. Within each display length category, every consonant was used once at each serial position. With the additional constraint that no letter could appear more than once in a given display, 100 different slides were made. Because of the limited capacity of the slide projector, one display in each of the size categories was discarded to yield a total of 95 displays in the experiment.

The apparatus employed included an automated dual tachistoscope previously described in a paper by Holmgren (1968). The displays were presented through a circular aperture onto a rear-projection ground-glass screen, illuminating an area $2-1 / 16$ in. in diam. The displays measured $3 / 16$ in. in height and varied in length from $7 / 8$ in. for a display of Size 5 to $3 / 8$ in. for a one-element display when projected on the screen. From a line of sight viewing distance of about $2 \mathrm{ft}$, the visual angle subtended by the largest display was approximately $2.2 \mathrm{deg}$.

Between stimulus exposures the screen was illuminated by a second projector. A single pre- and post-exposure field was used containing four small black dots forming a rectangle $7 / 8 \times 1 / 2 \mathrm{in}$. The display always appeared centered within this rectangle. The brightness of the pre- and post-exposure field as measured by a Macbeth illuminometer was $6.6 \mathrm{ft}-\mathrm{L}$, while display brightness averaged $7.4 \mathrm{ft}-\mathrm{L}$. Above the screen three small colored lights were arranged in a vertical row. Below the screen a single IEE Binaview character-display unit was used to present the critical letter on each trial.

On a table in front of $S$, three telegraph keys were arranged along an arc extending from 9 o'clock to 12 o'clock. The keys were positioned so that $S$ could rest her right arm comfortably on the table, with her right forefinger on the center key. By moving her hand along an arc $1 \mathrm{in}$. in either direction, $S$ could depress either of the two response keys. The Ss were randomly assigned to two groups. Those in Group 1 registered a positive response (indicating a match between the critical letter and one of the display letters) by depressing the key nearest to them, and a negative response by depressing the key nearest the display. These conditions were reversed for $\mathrm{Ss}$ in Group 2.

The displays were presented in a different random order for each $S$ and each session, with the constraint that each display size was shown equally often and each serial position contained the critical element equally often during the session. The target letter shown on each trial was chosen randomly from the set of non-display elements on negative trials and randomly from the set of display elements (with the above constraint) on positive trials. The sequence of positive and negative trials was random, with the restriction that there was an equal number of positive and negative trials during each session.

The following sequence of events occurred on each trial: (a) A 


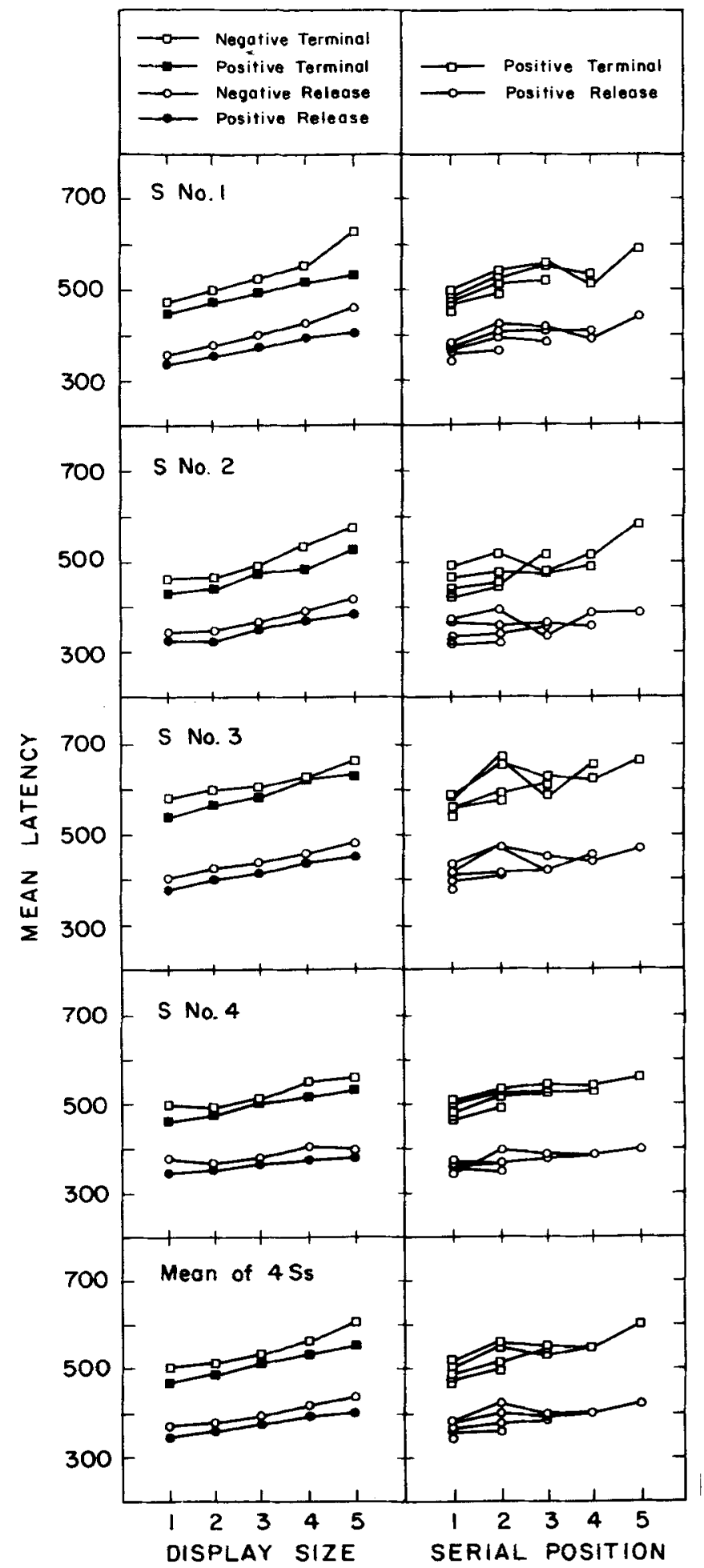

Fig. 2. Latency of positive and negative responses as a function of display size (left panel) and latency of positive responses as a function of the serial position of the critical element (right panel) for Ss in Group 1.

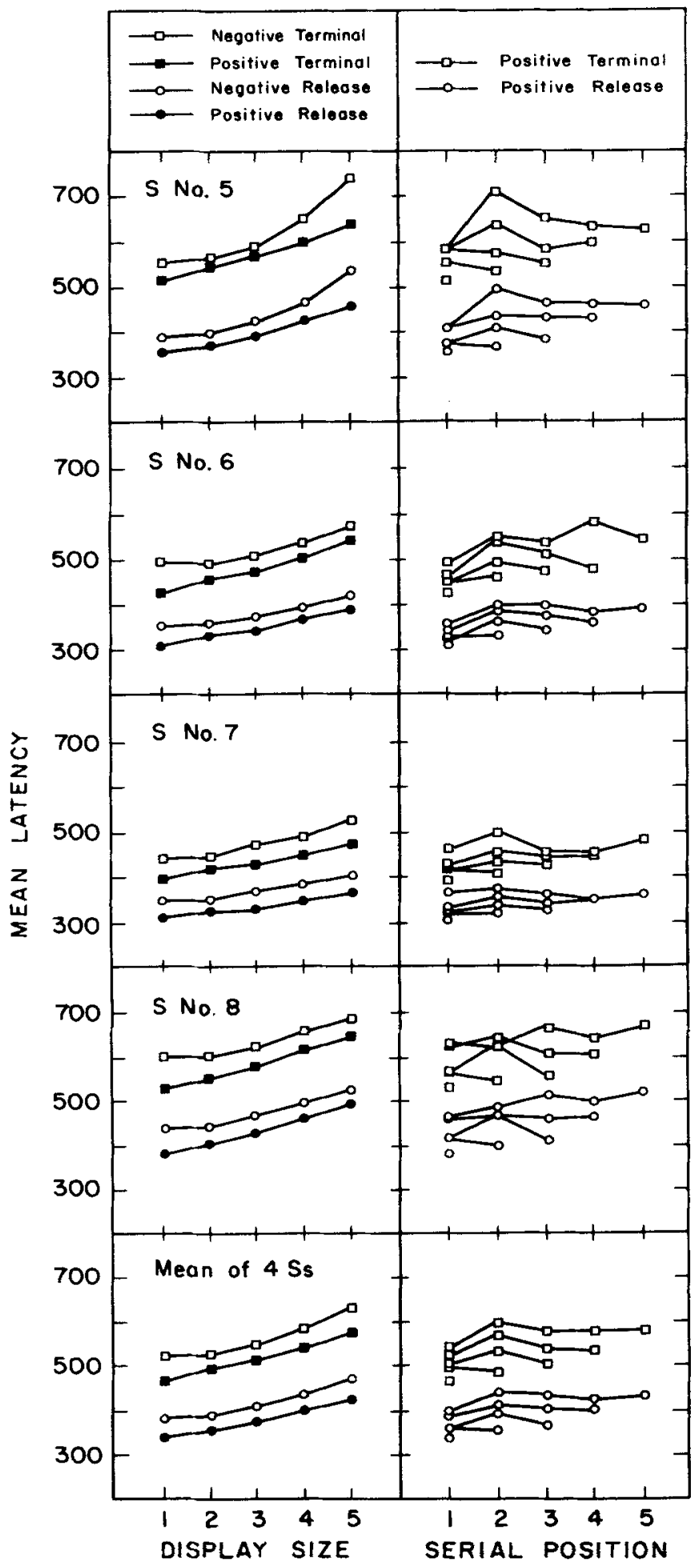

Fig. 3. Latency of positive and negative responses as a function of display size (left panel) and latency of positive responses as a function of the serial position of the critical element (right panel) for Ss in Group 2. 
Table 1

Proportions of False Positive (FP) and False Negative (FN) Responses for Each Display Size

\begin{tabular}{|c|c|c|c|c|c|c|c|c|c|c|c|c|}
\hline \multirow[b]{2}{*}{ Subject } & \multicolumn{2}{|c|}{1} & \multicolumn{2}{|c|}{2} & \multicolumn{2}{|c|}{$\underset{3}{\text { Display Size }}$} & \multicolumn{2}{|c|}{4} & \multicolumn{2}{|c|}{5} & \multicolumn{2}{|c|}{$\begin{array}{l}\text { Mean error rate for } \\
\text { all display sizes }\end{array}$} \\
\hline & FP & FN & FP & $\mathbf{F N}$ & FP & FN & FP & FN & $\mathbf{F P}$ & FN & FP & FN \\
\hline 1 & .015 & - & .007 & .014 & .014 & .038 & .031 & .034 & .035 & .028 & .020 & .023 \\
\hline 2 & - & - & - & .013 & .007 & .008 & .007 & .042 & .069 & .021 & .017 & .017 \\
\hline 3 & .007 & - & - & - & - & .023 & - & .014 & .028 & .014 & .007 & .009 \\
\hline 4 & - & - & .007 & - & .027 & .056 & .024 & .097 & .044 & .088 & .020 & .048 \\
\hline 5 & .007 & .006 & - & - & .007 & .013 & .008 & .029 & .008 & .035 & .006 & .017 \\
\hline 6 & - & - & - & - & - & .007 & - & .007 & .008 & - & .002 & .003 \\
\hline 7 & .014 & - & .029 & .029 & .007 & .020 & .028 & .007 & .028 & .043 & .021 & .020 \\
\hline 8 & - & - & .007 & .007 & .007 & .023 & .014 & .038 & .023 & .008 & .010 & .015 \\
\hline Group 1 & .006 & - & .005 & .007 & .012 & .031 & .016 & .047 & .044 & .038 & .017 & .025 \\
\hline $\begin{array}{l}\text { Group } 2 \\
\text { Overall }\end{array}$ & .005 & .002 & .009 & .009 & .005 & .016 & .012 & .020 & .017 & .022 & .010 & .014 \\
\hline means & .005 & .001 & .006 & .008 & .009 & .024 & .014 & .034 & .030 & .030 & .013 & .019 \\
\hline
\end{tabular}

single letter was presented for $2 \mathrm{sec}$ on the Binaview unit. (b) When the unit was turned off, $S$ pushed a button held in her left hand and, after a .5-sec delay, the display was presented for $400 \mathrm{msec}$. (c) Using her right hand $S$ then made the appropriate response within a 2-sec time limit after the onset of the display. (d) At the end of this period one of the three lights above the screen was turned on for 2 sec; a green light indicated a correct response, a red light indicated an error, and a white light indicated no response or a response made after the 2 -sec limit. After a .5-sec intertrial interval, a new target letter was presented on the Binaview unit to start the next trial. Each trial lasted between 7 and $8 \mathrm{sec}$ depending on the elapsed time between the offset of the Binaview unit and the pressing of the start button by $S$.

The onset of the display triggered two latency counters, one stopping when $S$ lifted her finger from the center key, and the other stopping when either the positive or negative response key was hit. In this way measures of release time and terminal response time were obtained.

The Ss were run for a total of 250 trials in each session. With a 5-min rest period after the first 130 trials, the session lasted about $40 \mathrm{~min}$. All Ss participated in nine sessions. Before each session Ss were instructed not to release the center key until they were certain of the correct response, and then to depress the appropriate key as rapidly as possible while being careful not to make errors. After each session $S$ received feedback from $E$ about her performance to insure rapid responding and a low error rate.

\section{RESULTS}

Mean latencies as a function of display size for both release responses and terminal responses are presented in Fig. 1. Release latency is the elapsed time between the onset of the display and the lifting of S's finger from the center key in initiating the terminal response. Terminal latency is the time between the onset of the display and the depression of the appropriate response key, i.e., release latency plus the additional travel time. Both release and terminal latencies were recorded separately for positive and negative trials, and all latency data presented here are based upon correct responses only. Data from the first day were discarded along with the first 10 trials of each subsequent session. Data from Sessions 2.9 were combined in pairs of consecutive days. Inspection of Fig. 1 suggests that latencies decreased over the first few sessions of the experiment, reaching a somewhat stable level by the fourth day. Consequently, further analysis was done on the combined data from Days 4 through 9 only.

Latencies as a function of display size are presented for Ss from Group 1 in the left panel of Fig. 2. The data for positive trials were further analyzed by plotting latency as a function of the serial position of the critical element within the display. The serial-position curves for release and terminal latencies for each $\mathrm{S}$ are shown in the right panel of Fig. 2. Figure 3 presents similar data for $S s$ in Group 2. The data from both groups were combined, and the mean latencies are shown in Fig. 4. The error rate for each $S$ and the SDs of response latencies are presented in Tables 1 and 2, respectively.

As can be observed in the left panels of Figs. 2-4, latency seems to be a linear function of display size. The best fitting straight lines were found for individual and grouped performance for positive and negative release latencies and positive and negative terminal latencies. The slopes and intercepts of these lines are presented in Table 3.

\section{DISCUSSION}

In a serial-scanning process, if the mean processing time is the same for all items, response latency is an increasing linear function of the number of display elements. If the scan is self-terminating, the slope of the positive response function will be half that of the negative line because, on the average, only half of the elements in a positive display are processed before the target is detected. If the scan is exhaustive all elements will be processed on every trial, and the positive and negative functions will have the same slope. As can be observed in Table 3 , the slopes for both positive and negative responses appear to be about the same, and (with the possible exception of $S$ No. 5) the scan is clearly not self-terminating. Another argument against the self-terminating hypothesis could be based upon the flatness of the serial-position curves (right panels of Figs. 2-4). Given a strict self-terminating scan that begins with the element at the left side of the display and proceeds serially to the right, the serial-position curves would all have the same slope and intercept. If, however, the scan begins at a random starting point within the display, the serial-position curves would be flat and indistinguishable from those generated by an exhaustive scan. Therefore, the obtained serial-position curves cannot alone be taken to contradict a serial and self-terminating scanning model, but together with the obtained functions for positive and negative response data it may be concluded that, despite some reports favoring the self-terminating model (Estes \& Wessel, 1966; Nickerson, 1966; Sternberg, 1967), the evidence from the present study seems to invalidate that hypothesis.

Table 2

Standard Deviations of Response Latencies Across Subjects (in Msec.)

\begin{tabular}{llccccc}
\hline & & \multicolumn{5}{c}{ Display Size } \\
\hline \multirow{3}{*}{ Release } & Positive & 27.0 & 31.9 & 33.9 & 38.6 & 44.3 \\
& Negative & 32.1 & 35.0 & 36.9 & 40.2 & 52.4 \\
\multirow{3}{*}{ Terminal } & Positive & 51.4 & 53.9 & 55.5 & 62.4 & 61.2 \\
& Negative & 55.2 & 58.1 & 54.4 & 58.5 & 69.7 \\
\hline
\end{tabular}


Table 3

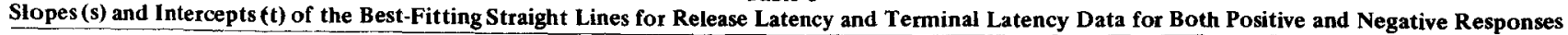

\begin{tabular}{|c|c|c|c|c|c|c|c|c|c|c|c|c|}
\hline \multirow[b]{2}{*}{ Subject } & \multicolumn{6}{|c|}{ Release Response } & \multicolumn{6}{|c|}{ Terminal Response } \\
\hline & $s+$ & $\mathrm{t}+$ & $\mathbf{s}^{-}$ & $\mathrm{t}^{-}$ & $\mathbf{s}^{-}-\mathbf{s}^{+}$ & $t^{-} \ldots t+$ & $s+$ & $t+$ & $\mathrm{s}^{-}$ & $\mathrm{t}^{--}$ & $s^{-}-s^{+}$ & $t^{-}-t^{+}$ \\
\hline $\begin{array}{l}1 \\
2 \\
3 \\
4 \\
5 \\
6 \\
7 \\
8\end{array}$ & $\begin{array}{r}17.4 \\
15.3 \\
18.6 \\
8.9 \\
25.4 \\
19.1 \\
13.9 \\
28.2\end{array}$ & $\begin{array}{l}325 \\
309 \\
363 \\
339 \\
325 \\
290 \\
292 \\
351\end{array}$ & $\begin{array}{r}22.9 \\
20.1 \\
18.7 \\
7.8 \\
35.7 \\
16.5 \\
14.8 \\
22.5\end{array}$ & $\begin{array}{l}338 \\
307 \\
386 \\
363 \\
336 \\
329 \\
324 \\
408\end{array}$ & $\begin{array}{r}5.5 \\
4.8 \\
0.1 \\
-1.1 \\
10.3 \\
-2.6 \\
0.9 \\
-5.7\end{array}$ & $\begin{array}{l}13 \\
-2 \\
23 \\
24 \\
11 \\
39 \\
32 \\
57\end{array}$ & $\begin{array}{l}21.3 \\
22.4 \\
23.1 \\
17.8 \\
29.6 \\
27.7 \\
18.6 \\
29.8\end{array}$ & $\begin{array}{l}433 \\
398 \\
520 \\
446 \\
486 \\
395 \\
375 \\
496\end{array}$ & $\begin{array}{l}35.0 \\
28.7 \\
18.8 \\
18.0 \\
45.3 \\
19.0 \\
21.5 \\
22.9\end{array}$ & $\begin{array}{l}433 \\
413 \\
561 \\
469 \\
484 \\
462 \\
408 \\
564\end{array}$ & $\begin{array}{r}13.7 \\
6.3 \\
-4.3 \\
0.2 \\
15.7 \\
-8.7 \\
2.9 \\
-6.9\end{array}$ & $\begin{array}{r}0 \\
15 \\
41 \\
23 \\
-2 \\
67 \\
33 \\
68\end{array}$ \\
\hline $\begin{array}{l}\text { Group } 1 \\
\text { Group } 2\end{array}$ & $\begin{array}{l}15.0 \\
21.6\end{array}$ & $\begin{array}{l}334 \\
314\end{array}$ & $\begin{array}{l}17.4 \\
22.4\end{array}$ & $\begin{array}{l}348 \\
349\end{array}$ & $\begin{array}{l}2.3 \\
0.7\end{array}$ & $\begin{array}{l}14 \\
35\end{array}$ & $\begin{array}{l}21.2 \\
26.4\end{array}$ & $\begin{array}{l}449 \\
438\end{array}$ & $\begin{array}{l}25.1 \\
27.2\end{array}$ & $\begin{array}{l}469 \\
480\end{array}$ & $\begin{array}{l}4.0 \\
0.8\end{array}$ & $\begin{array}{l}20 \\
42\end{array}$ \\
\hline Overall means & 18.3 & 324 & 19.9 & 348 & 1.5 & 25 & 23.8 & 444 & 26.2 & 474 & 2.4 & 31 \\
\hline
\end{tabular}

In view of the apparent incompatibility between the present results and those obtained by Nickerson (1966) and Sternberg (1967), the data from the latter studies were examined for those conditions common to the present experiment. The results obtained by Nickerson and Sternberg were plotted, as in Fig. 4, for the case in which a single item was presented as the critical element and a display containing several items was presented as the field to be scanned. When plotted in this manner, it cannot be conclusively argued that either a self-terminating or an exhaustive serial model can handle their results.

The present data seem to be explained well by a serial-exhaustive scanning model. To obtain the theoretical predictions for this model, the lines of best fit were found for both release latencies and terminal latencies for the data in Fig. 4 by simultaneously minimizing the squared deviations for positive and negative responses. The obtained slopes were 19.1 for release data and 25.0 for terminal data; the intercepts were 324 for positive release data, 348 for negative, 444 for positive terminal data, and 474 for negative. The fit of these theoretical lines to the data is shown in Fig. 5. Except for the negative terminal latency data, the fit seems to be exceptionally good. Figure 5 also presents the theoretical serial-position curves; the discrepancy between theory and data here is due mainly to the fact that for the three largest display sizes, Ss responded substantially faster when the critical element was the first letter on the left than when it was in any other position. It is possible that when a match is detected in the first position, Ss have a slight tendency to terminate their scan before processing the whole display.

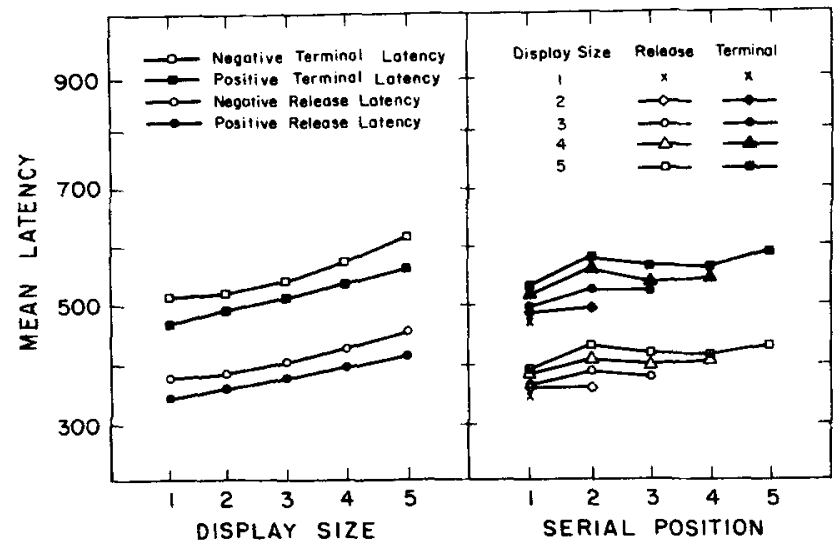

Fig. 4. Latency of positive and negative responses as a function of display size (left panel) and latency of positive responses as a function of the serial position of the critical element (right panel) averaged over all Ss.
The fact that the slope for the terminal response data is significantly greater than the slope for the release data indicates that the release time may not be a valid measure of the termination of the scanning process. The difference in slopes of $5.9 \mathrm{msec}$ may be due to a premature release for larger display sizes, with $\mathrm{S}$ deciding which response to make after initiating the release response.

There are some differences between Groups 1 and 2 in the present study, particularly in the slopes of the best-fitting lines. This result may be interpreted in terms of findings from a previous study (unpublished) in which response keys were located to the left and right of the center key as $S$ faced the screen. In this case, as display size increased, both release and terminal latencies increased at a relatively faster rate if the positive key was located to the right rather than to the left of the center key. The Ss for whom the positive key was on the right reported that they felt they were scanning from left to right and that the position of the response keys was incompatible with this type of scan, i.e., it seemed to be difficult to scan through the list to the right side of the display and, having not detected the critical element, initiate a left response. In the present study, while not having eliminated the effects of possible response incompatibility, the differences between the two groups are much less.

In the previous study, the exposure time for the display was considerably less than in the present study (i.e., $150 \mathrm{msec}$ vs $400 \mathrm{msec}$ ). Figure 6 presents release and terminal latencies for positive and negative responses as a function of display size, averaged over the eight $S s$ in that study. Also shown are the

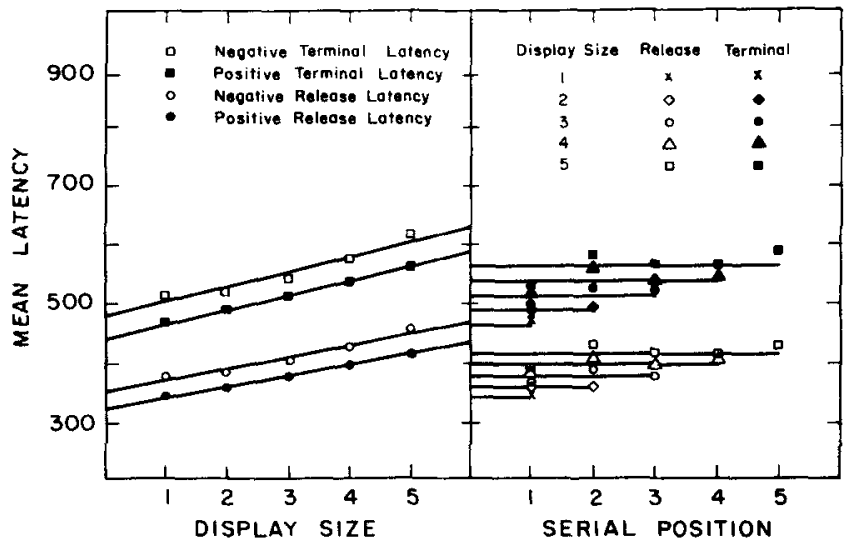

Fig. 5. Latency of positive and negative responses as a function of display size (left panel) and latency of positive responses as a function of the serial position of the critical element (right panel) averaged over all Ss. The solid lines represent the values predicted by the serial-exhaustive scanning model. 


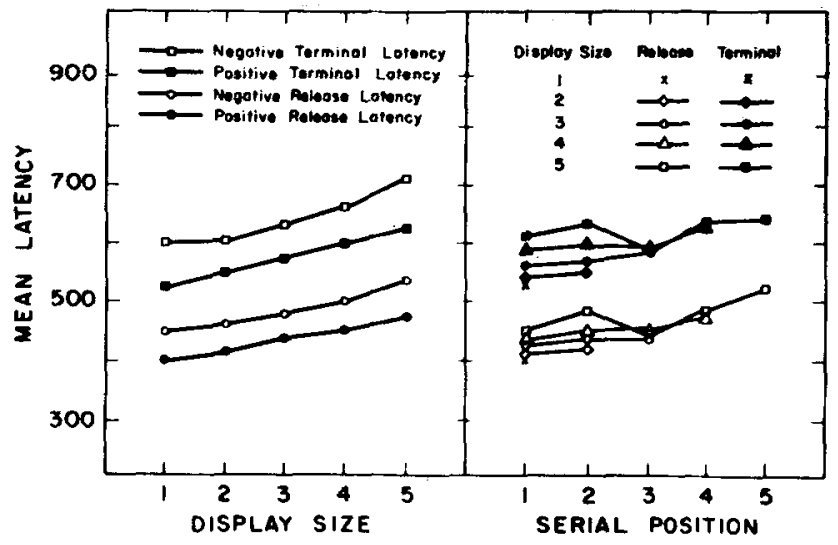

Fig. 6. Latency of positive and negative responses as a function of display size (left panel) and latency of positive responses as a function of the serial position of the critical element (right panel) averaged over eight $\mathrm{Ss}$ in a previous study.

average serial-position curves. Slight qualitative differences may be observed between the serial-position curves shown in Fig. 6 and those obtained in the present study. These may be explained, in part, by the fact that central fixation points (above and below the center display letter) were used in the previous study, but they were eliminated for the experiment reported here. No major qualitative differences were observed between the results of the two studies, the only differences being lower error rates $(2.6 \%$ as compared with $1.6 \%$ in the present study) and faster latencies when using the longer exposure time. The slopes of the lines obtained in the two studies are remarkably similar (18.4 and 21.6 for positive and negative release latencies, and 24.5 and 28.6 for positive and negative terminal latencies, respectively, as compared with $18.3,19.9,23.8$, and 26.2 obtained in the present study). Therefore, while the exposure time in this study was long enough to allow more than one fixation, it is unlikely that Ss were changing their fixation point before initiating a response.

While the serial-exhaustive scanning model predicts the overall results of the present study, a parallel scanning model may also be used to make the same predictions. Sternberg $(1966,1967)$ has rejected a parallel scanning model because of the linear increase in latency with increasing display size. He argues that if items are processed independently and the processing time for each item has a non-zero variance, then for any parallel model there is an upper bound on the negative latency curve that falls below the best-fitting linear function. However, if the independence requirement is relaxed, it can be shown that there are parallel models that make exactly the same predictions as the serialexhaustive model. As an example of such a parallel process, consider a model in which during any small time interval $h$, each item has a probability $\lambda h /(d-i)$ of completing processing, where $d$ is the number of items in the display and $i$ is the number of elements that have already completed processing. It can be shown that in this case the mean time to process all items is $d / \lambda$. Thus, if $S$ does not respond until all items have been processed, both positive and negative response latencies will increase linearly with display size and the two lines will have the same slope. This can be viewed as a model in which $S$ has a fixed amount $\lambda$ of "processing energy" that is distributed over those items that have not yet been processed. It can be shown that the predictions presented above are independent of how the processing energy is distributed over the elements being processed at any point in time.

In conclusion, it is clear that a serial, self-terminating scanning model is inadequate to handle the results of the present study. Of course there is no question that in a task requiring multiple eye fixations, such as scanning a long list of items (Neisser, 1963), the search terminates with the processing of the target item. However, it is doubtful that models developed for these types of tasks are directly applicable to the processing of information available in briefly presented displays. The question of whether or not information obtained in a single eye fixation is processed exhaustively has not been decisively answered, despite the fact that an exhaustive serial scanning model predicts most of the data obtained here. Some value is seen in further investigation of parallel models for visual detection tasks in which the distinctions made between exhaustive and self-terminating versions of the process are not clearly evident; indeed there may be no distinction between them if processing times are completely dependent. An experiment is currently in progress where the number of critical elements is varied within a fixed display size. The effects of target redundancy on response latency should yield further insights into the nature of the scanning process, perhaps providing evidence for a more general processing model and deciding the issue of self-terminating vs exhaustive processing.

\section{REFERENCES}

ESTES, W. K., \& TAYLOR, H. A. A detection method and probabilistic models for assessing information processing from brief visual displays. Proceedings of the National Academy of Sciences, 1964, 52, No.2, 446-454.

ESTES, W. K., \& TAYLOR, H. A. Visual detection in relation to display size and redundancy of critical elements. Perception \& Psychophysics, $1966,1,9-16$.

ESTES, W. K., \& WESSEL, D. L. Reaction time in relation to display size and correctness of response in forced-choice visual signal detection. Perception \& Psychophysics, 1966, 1, 369-373.

HOLMGREN, J. Visual search with imperfect recognition. Perception \& Psychophysics, 1968, 4, 247-252.

NEISSER, U. Decision time without reaction time: Experiments in visual scanning. American Journal of Psychology, 1963, 76, 376-385.

NICKERSON, R. S. Response times with a memory-dependent decision task. Journal of Experimental Psychology, 1966, 72, 761-769.

STERNBERG, S. High-speed scanning in human memory. Science, 1966, $153,652-654$.

STERNBERG, S. Scanning a persisting visual image versus a memorized list. Paper presented at the annual meeting of the Eastern Psychological Association, 1967.

NOTES

1. This research was supported by Grant NGR-05-020244 from the National Aeronautics and Space Administration.

2. Address: Department of Psychology, Stanford University, Stanford, California 94305.

(Accepted for publication March 27, 1969.) 